\title{
A novel stability-indicating method for determination of a new antidepressant effect of vortioxetine in a pharmaceutical formulation by using RP-HPLC
}

\author{
Gizem Tiris $^{1,2^{*}}$ (D), Cansu Alver ${ }^{1}$ and Nevin Erk ${ }^{1 *}$
}

\begin{abstract}
Background: A novel rapid, accurate, and stability-indicating reversed-phase high performance liquid chromatographic (RPHPLC) and first derivative spectrophotometric determination were explained for the assay of vortioxetine (VRT) in bulk and pharmaceutical formulations. For RP-HPLC method, optimal separation and determination of VRT were achieved with a Waters Symmetry $C_{18}(100 \times 4.6 \mathrm{~mm}, 3.5 \mu \mathrm{m})$ analytical column using a mobile phase consisting of methanol:0.05 $\mathrm{M}$ potassium dihydrogen phosphate (pH:3.0 \pm 0.05$)(30: 70, \mathrm{v} / \mathrm{V})$ in isocratic mode with flow rate of $1.3 \mathrm{~mL} \mathrm{~min}{ }^{-1}$. Injection volume was $20 \mu \mathrm{L}$. The maximum absorption wavelength of VRT is $225.0 \mathrm{~nm}$; hence, $225.0 \mathrm{~nm}$ was studied as the detection wavelength and column at $50^{\circ} \mathrm{C}$ temperature. The caffeine was used as the internal standard (IS). On the other hand, the first derivative spectrophotometric method for the analysis of vortioxetine was performed by measuring the amplitude at 251.7 and $272.6 \mathrm{~nm}$.

Result: The HPLC method was found to be linear in the concentration ranges of 10.0-70.0 $\mathrm{mg} \mathrm{mL}^{-1}$ with the coefficient value $R^{2}$ of 0.9998 , and the mean recovery value was $100.7 \%$. Further stability studies were done through exposure of the analyte solutions to various stress conditions: acid, alkali hydrolysis, chemical oxidation, and exposure to UV radiation. For the first derivative spectrophotometric method, linearity was observed in the concentration range $6.0-30.0 \mu \mathrm{g} \mathrm{mL}^{-1}$ (for $237.7 \mathrm{~nm}$ $R^{2}=0.9999$ and for $\left.257.2 \mathrm{~nm} R^{2}=0.9997\right)$.
\end{abstract}

Conclusion: The methods were validated in accordance with ICH guidelines with respect to linearity, accuracy, specificity, limit of detection, precision, and limit of quantification.

Keywords: Vortioxetine, Caffeine, First derivative spectrophotometry, Stability-indicating, RP-HPLC

\section{Background}

Vortioxetine (VRT) (Fig. 1) is the first in a novel group of drugs known as a serotonergic (5-HT) antidepressant, chemically known as 1-[2-(2,4-dimethylphenylsulfanyl)phenyl]-piperazine. Vortioxetine (VRT) binds with high affinity to the serotonin transporter and its antidepressant effects are considering to be secondary to enhancing serotonin in the central nervous system by way of

\footnotetext{
*Correspondence: gizem.tiris@gmail.com; erknev94@gmail.com

'Faculty of Pharmacy, Department of Analytical Chemistry, Ankara University, Tandoğan, Ankara, Turkey

Full list of author information is available at the end of the article
}

inhibition of reuptake [1]. Providers may consider $5 \mathrm{mg}$ per day for patients who cannot tolerate higher doses. VRT can be stopped abruptly, but a reduction to $10 \mathrm{mg}$ per day is recommended for patients taking $15 \mathrm{mg}$ or more per day for a week before complete [2-5].

A new film-coated tablet of VRT has been newly developed by Lundbeck Pharm. Pharmacopeias do not provide any monographs for VRT and pharmaceutical dosage form. Until now, no references describing of VRT in degradation studies have been found in the literature. UPLCMS/MS method was reported for the determination of VRT in rat and human plasma [6, 7]. Additionally, a few 


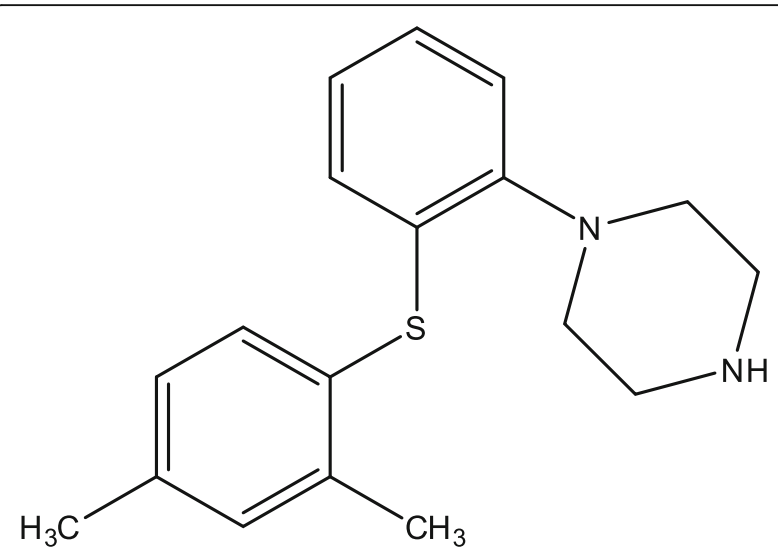

Fig. 1 Structure of vortioxetine

methods were presented for the quantitative determination of vortioxetine and its major human metabolite in biological fluids besides analyzing tablets and impurities using LC-MS [8-12], LC-MS/MS [13-16], HPLC [17-19], and HILIC-MS [20]. Spectrophotometric UV-metric and potentiometric $\mathrm{pH}$-metric methods were used for the determination of VRT [21].

In the current study, the RP-HPLC assay of VRT in the film-coated tablets was optimized and validated. The presented method was carried out for the determination of VRT under different stressed conditions in addition to the analysis of coated tablet forms. A stabilityindicating method has not been described in any of the cited literature, so the optimization of a rapid, accurate, precise, and specific stability-indicating RP-HPLC method for the quantitation of VRT in coated tablet dosage forms is required.

\section{Methods}

\section{Chemicals}

Vortioxetine reference substance was supplied from Lundbeck Pharm. Ind. The purity of the drug is $98.87 \%$. A commercial preparation, Brintellix ${ }^{\bullet}$ film-coated tablets (produced by Lundbeck Pharm. Ind., Turkey, containing $10.0 \mathrm{mg}$ of VRT per coated tablet) was assayed. Methanol, potassium dihydrogen phosphate, ammonium acetate, and acetonitrile of HPLC grade were received from Merck Chem. Ind. All reagents employed in this study were of analytical-reagent grade.

\section{Apparatus}

Instrument used in the study was Dionex Ultimate focused 3000-9 equipped with auto sampler and DAD. The wavelength of the UV detector was set at $225.0 \mathrm{~nm}$. Peak areas were integrated by using the computer Chromeleon Client software program. Absorbance measurements were measured on a double beam UV-VIS spectrophotometer model UV-1601 by using quartz cells with $10.0 \mathrm{~mm}$ path length.

\section{Chromatographic conditions}

An isocratic mobile phase consisted of potassium dihydrogen phosphate buffer $(\mathrm{pH}: 3.0 \pm 0.05)$ :methanol in the ratio (30:70 volumetric ratio) filtered and degassed through a membrane filter of $0.45 \mu \mathrm{m}$ porosity before use. The analytical column was a Waters Symmetry RP$18(3.5 \mu \mathrm{m}, 100 \mathrm{~cm} \times 4.6 \mathrm{~mm})$ column. The flow rate of $1.3 \mathrm{~mL} \mathrm{m^{-1 }}$ and the detector was set at $225.0 \mathrm{~nm}$. All determinations were made at $50{ }^{\circ} \mathrm{C}$ and the injection volume was $20.0 \mu \mathrm{L}$. The working solutions and mobile phases were prepared daily.

\section{Construction of the calibration graph and linearity}

For the HPLC method, the standard stock solution was prepared separately by dissolving VRT and caffeine (CAF) (internal standard) in the degassed mobile phase, respectively. Based on these stock solutions, the working standard solution, VRT, was prepared in a linear working range of $10.0-70.0 \mu \mathrm{g} \mathrm{mL}^{-1}$ and caffeine as internal standard at the amount of $20.0 \mu \mathrm{g} \mathrm{mL}^{-1}$ into $10.0 \mathrm{~mL}$ volumetric flasks using the mobile phase. Five replicate measurements were made for all concentrations. The injection volume of each sample is $20 \mu \mathrm{L}$. To calculate the concentration of VRT, the ratio of VRT to IS peak area was calculated. The linear working graph was constructed and the calibration equal was then stored. In the first derivative spectrophotometric method, Beer's law range, linear regression equations, and correlation coefficients determined.

\section{Validation parameters Accuracy as recovery}

The accuracy of the suggested method has quantified the percentage of analytical recovery of VRT by using the standard addition method. The recovery test was performed at three levels: $30.0,40.0$, and $50.0 \mu \mathrm{g} \mathrm{mL}^{-1}$ of the pure sample. Five replicate experiments were performed and recoveries (\%), RSD (\%) were found.

\section{Precision}

So as to control the precision experiment, intraday and inter-day experiments were evaluated. The method was found to be in precision at three different independent (low, medium, and high) amounts during the same day, and 5 different days. The relative standard deviations were found.

\section{Sensitivity}

The LOD and LOQ parameters were estimated as described at $\mathrm{ICH}$ guidelines by the formulas given below; where $S_{b}$ is 
the standard deviation of the intercept of the linear line and $a$ is the slope of the regression equation [22].

$$
L O D=3.3 S_{b} / a \quad ; \quad L O Q=10 S_{b} / a
$$

\section{Robustness}

The robustness of the proposed RP-HPLC method was carried out by altering the experimental conditions such as analytical column, column temperature, flow rate, changing $\mathrm{pH}$, and mobile phase. The robustness of the derivative spectrophotometric method was established by introducing small changes in experimental conditions like wavelength $\pm 1 \mathrm{~nm}$. Making a deliberate change in wavelength was taken place and RSD of absorbance found to be less than 2 , specify that the method was robust.

\section{Degradation studies}

Degradation studies were conducted to determine specificity and stability-indicating properties of the suggested method. That these stress conditions were performed under the following acidic, alkaline, oxidative, and photodegradation conditions. VRT $(20.0 \mathrm{mg})$ and CAF $(20.0 \mathrm{mg})$ were exactly weighed. The weighed active ingredients were taken into $100.0 \mathrm{~mL}$ volumetric flasks and diluted with the mobile phase and made up to its volume. The prepared stock solutions were used of forced degradation experiments.

For acidic or alkaline degradation studies, $1.0 \mathrm{~mL}$ of standard stock VRT solution was transferred to a 10.0$\mathrm{mL}$ volumetric flask in the presence of IS. A total of 2.0 $\mathrm{mL}$ of $0.1 \mathrm{M} \mathrm{HCl}$ or $0.1 \mathrm{M} \mathrm{NaOH}$ solution was added and stirred. The volumetric flask was heated in the water bath at $80^{\circ} \mathrm{C}$ for $1 \mathrm{~h}$, cooled to room temperature, and neutralized with $0.1 \mathrm{M} \mathrm{NaOH}$ or $0.1 \mathrm{M} \mathrm{HCl}$ to $\mathrm{pH} 7.0$. The above solution has diluted the volume with the mobile phase.

For the oxidation degradation study, $1.0 \mathrm{~mL}$ of standard stock solution of VRT in the presence of IS was transferred into a $10.0-\mathrm{mL}$ volumetric flask. A total of $2.0 \mathrm{~mL}$ of $3.0 \mathrm{H}_{2} \mathrm{O}_{2}$ solution was added and mixed well. The volumetric flask was heated in the water bath at $80^{\circ} \mathrm{C}$ for $1 \mathrm{~h}$, cooled to room temperature. The above solution has diluted the volume with the mobile phase.

For photodegradation study, analytically pure sample of VRT and CAF were transferred into a petri dish and exposed into the sunlight for $48 \mathrm{~h}$. The solids were dissolved with the mobile phase.

Filter the degradation solutions with $0.45-\mu \mathrm{m}$ syringe filters and place in vials of the RP-HPLC system for all degradation studies.

\section{Application to pharmaceutical formulation}

At first, ten tablets of Brintellix were weighed and finely powdered in a mortar. The contents were diluted with the mobile phase. Quantity of one tablet weigh was weighed and diluted with the mobile phase in a 100.0$\mathrm{mL}$ volumetric flask. The volumetric flask was shaken for $20.0 \mathrm{~min}$ by an ultrasonic shaker. The excipient was separated by filtration. After the filtration process, the appropriate volume of filtered solution and IS was transferred into a $100.0-\mathrm{mL}$ volumetric flask and completed with the mobile phase. All solutions were filtered through $0.45 \mu \mathrm{m}$ Millipore membrane filters before injections into the HPLC system. The concentration of VRT was calculated by calibration graph prepared with stock solution.

\section{Results}

The proposed RP-HPLC method was applied for the amount of VRT in pharmaceutical formulation. To optimize the RP-HPLC assay parameters, various variables effect on peak shape, retention, and resolution as well as suitable internal standard was investigated. As stationary phase, Waters - Symmetry $\mathrm{C}_{18}(150 \mathrm{~mm} \times 4.6$ $\mathrm{mm}, 3.5 \mu \mathrm{m})$, Luna ${ }^{\circ} \mathrm{C}_{18}(3.0 \mu \mathrm{m}, 4.6 \times 50 \mathrm{~mm})$ and Kromasil ${ }^{\circ} \mathrm{C}_{18},(3.5 \mu \mathrm{m}, 4.6 \times 100 \mathrm{~mm})$ column were tested so as to obtain a sharp peak. The results obtained in the different stationary phases were presented below in Table 1 . The best results were achieved by using Waters Symmetry $\mathrm{C}_{18}$.

A series of aqueous mobile phases containing buffer solutions and methanol were tested in the initial stage as mobile phase, different combinations of organic modifiers, buffer solutions in different $\mathrm{pH}$ values and flow rate effects were examined. DAD detector was set at $220.0,223.0,225.0,230.0$, and $235.0 \mathrm{~nm}$ for all conditions that the optimum wavelength was found to be $225.0 \mathrm{~nm}$. The $\mathrm{pH}$ of the mobile phase was changed over the range of 3.0-6.0 that the optimum $\mathrm{pH}$ was found to be 3.0. The best separation was attained when using a mobile phase combination of $0.05 \mathrm{M} \mathrm{KH}_{2} \mathrm{PO}_{4}$ :methanol (30:70, by volume ratio). Different internal standards were investigated to achieve the best resolution between VRT and the internal standard, and CAF was selected as an internal standard.

The column temperature effect on retention and resolution of VRT and CAF (IS) was examined, and no

Table 1 System suitability parameters

\begin{tabular}{lll}
\hline Columns & $\begin{array}{l}\text { Tailing } \\
\text { factor }\end{array}$ & $\begin{array}{l}\text { Theoretical plate } \\
\text { number }\end{array}$ \\
\hline Luna $C_{18}, 3.0 \mu \mathrm{m}, 4.6 \times 50 \mathrm{~mm}$ & 0.45 & 1092 \\
Kromosil $\mathrm{C}_{18}, 3.5 \mu \mathrm{m}, 4.6 \times 100 \mathrm{~mm}$ & 0.42 & 2285 \\
$\begin{array}{l}\text { Waters Symmetry } \mathrm{C}_{18}, 3.5 \mu \mathrm{m}, 4.6 \times 0.99 \\
100 \mathrm{~mm}\end{array}$ & 2402 \\
\hline
\end{tabular}




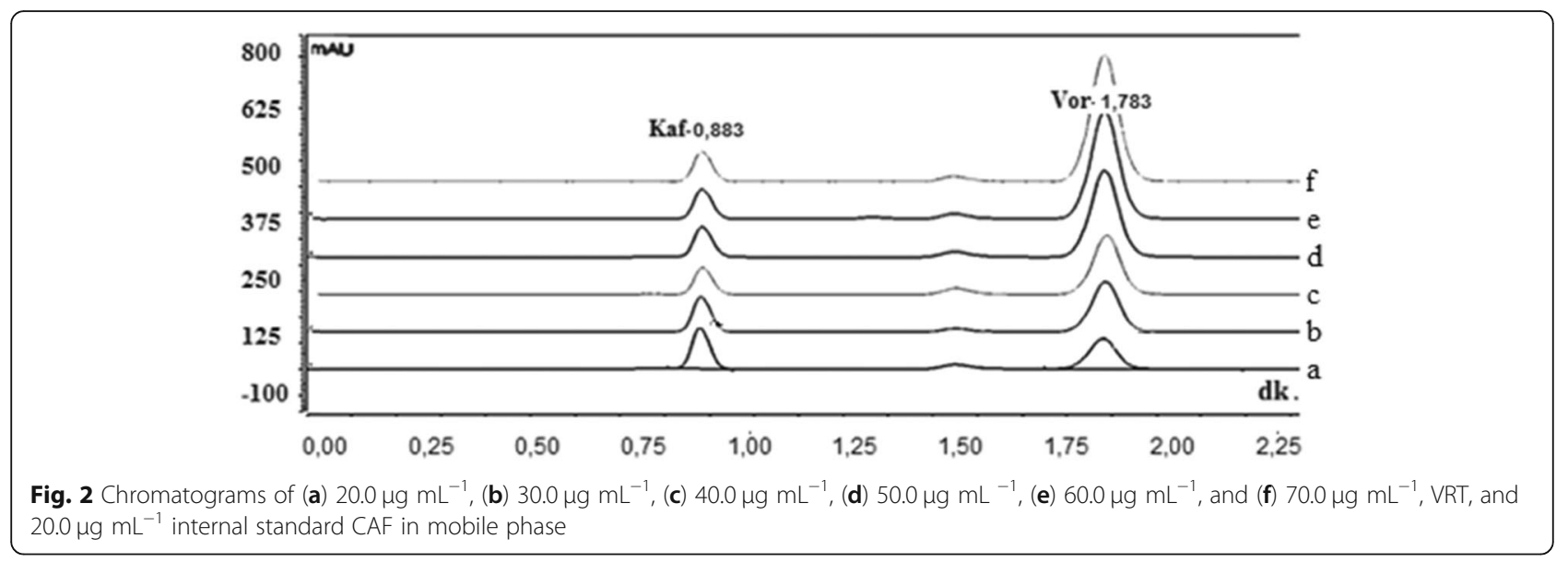

significant effect was detected from the range between $20-60^{\circ} \mathrm{C}$. Therefore, all investigations were performed at $50^{\circ} \mathrm{C}$. The UV detection was carried out at $225.0 \mathrm{~nm}$ because it showed the greatest response that was preferred for studies. Under the previously optimized conditions, the retention times of VRT and CAF (IS) were 0.88 and $1.78 \mathrm{~min}$; in this way, chromatographic separation was finished within $2.0 \mathrm{~min}$ (Fig. 2). Both VRT and CAF separated as a clear symmetrical peaks (symmetry factor of 0.91 and 1.11 for VRT and CAF, respectively) which were well separated with minimal tailing and good resolution.

Subsequently, the degradation of sample solutions under stress conditions was analyzed. The thermal, acid, base, oxidative, and photolytic degraded solutions of VRT and CAF pass the purity test (Table 2). The respective distinct chromatograms were shown in Fig. 3. During the degradation study, VRT was been degraded higher in oxidation condition and was found to be stable in thermal, acid, base, and photolytic conditions.

On the other side, the first derivative spectrophotometric method, $0.02 \mathrm{M}$ acetate buffer was chosen as a solvent system on account of its lack of interference, dissolves easily, suitability for routine quantitative determination of VRT. The zero-order UV spectrum and the first derivative spectrum of VRT in $0.02 \mathrm{M}$ acetate buffer are shown in Fig. 4. In the zero-order UV spectra of VRT show a broad peak around $228.0 \mathrm{~nm}$ and shoulder

Table 2 Summary of degradation studies

\begin{tabular}{llll}
\hline Conditions & Temperature $\left({ }^{\circ} \mathbf{C}\right)$ & Time $(\mathbf{h})$ & Degradation (\%) \\
\hline Thermal & 80 & 48 & -2.25 \\
Acid & 100 & 1 & +1.53 \\
Base & 100 & 1 & +0.70 \\
Oxidation & 100 & 1 & -100.00 \\
Photolytic & 100 & 1 & -1.51 \\
\hline
\end{tabular}

around $210.0 \mathrm{~nm}$. Vortioxetine derivative spectra of different degrees were plotted and the best peaks at 237.7 and $257.2 \mathrm{~nm}$ in the first derivative curve were obtained with convenient precision.

The proposed methods were validated, and the validation characteristics containing precision, linearity, accuracy, limit of detection (LOD), limit of quantification (LOQ), specificity, and applicability in pharmaceutical formulations were evaluated. To test the linear working curves for both proposed methods chromatograms and spectrums were analyzed in triplicate in seven different concentrations of VRT. The characteristics of the calibration curves are shown in Table 3. Under the experimental conditions, LOD and LOQ were determined to evaluate the detectivity of the proposed methods.

The precision of the repeatability (intra-day) and intermediate precision (inter-day) of the method was evaluated for VRT at three different independent concentrations by using HPLC and derivative method. From the results obtained, \% RSD was calculated and was found to be between 0.19 and $0.53 \%$ for intra-day variability and 0.34 and $0.57 \%$ for inter-day. Further \% RSD was calculated for derivative spectrophotometry. Then, the obtained values for the precision were shown in Table 4.

\section{Assay application}

The suggested methods were successfully implemented of VRT in marketed pharmaceutical preparation (Brintellix ${ }^{\circ}$ ). No pretreatment like time-consuming extraction or evaporation step was performed for specimen preparation. Experiments were realized under the same conditions as employed for the VRT. There is no chromatographic interference found for tablet dosage forms with internal standard, formulation components. The results given in Table 5 indicate good accuracy for pharmaceutical preparations. The accuracy of the described methods was quantified by its recovery results. 

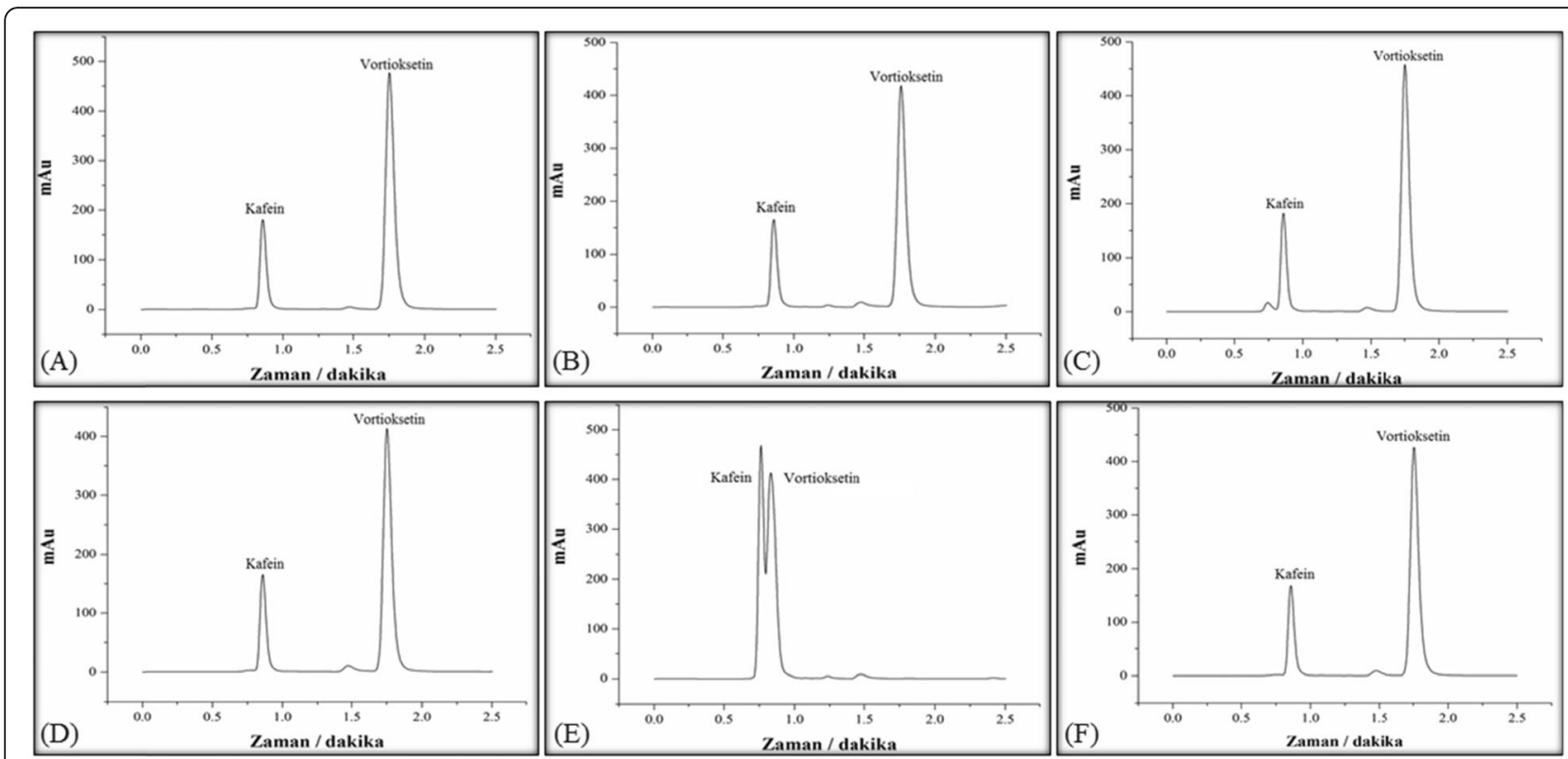

Fig. 3 Chromatograms of VRT and CAF in mixture (b: acid, c: base, $\mathbf{d}$ : thermal, e: oxidation, f: photolytic) (a: non-degradation)

To check the validity, the accuracy of the proposed methods is represented and determined by recovering VRT from the placebo. The recovery test was performed by adding different amounts of VRT with a concentration range of $5.0-40.0 \mu \mathrm{g} \mathrm{mL}^{-1}$ to the previously analyzed tablets and finally analyzing the amount recovered or VRT during studies. Recovery of the VRT was calculated as $97.7-102.9 \%$ for added drugs. The data obtained by the first derivative spectrophotometric method and RP-HPLC data were compared by using Student's $t$ test and the $F$ test at $95 \%$ confidence level. As can be seen from Table 6 , the estimated $t$ and $F$ values ( 0.80 and 1.30 respectively) did not exceed the theoretical values, indicating that there was no substantial difference between the described methods on account of accuracy. These results indicating that there is no substantial difference that exists between the performances of the two proposed methods regarding their accuracy and precision.

\section{Discussion}

In this study, chromatographic and spectrophotometric methods were optimized for the quantification of vortioxetine active substance in Brintellix preparation.

RP-HPLC and spectrophotometric methods were optimized. Various experiments have been conducted to optimize the chromatographic method. In order to optimize the RP-HPLC assay parameters, various variable effects on peak shape, retention, and resolution as well as suitable internal standard were investigated. The
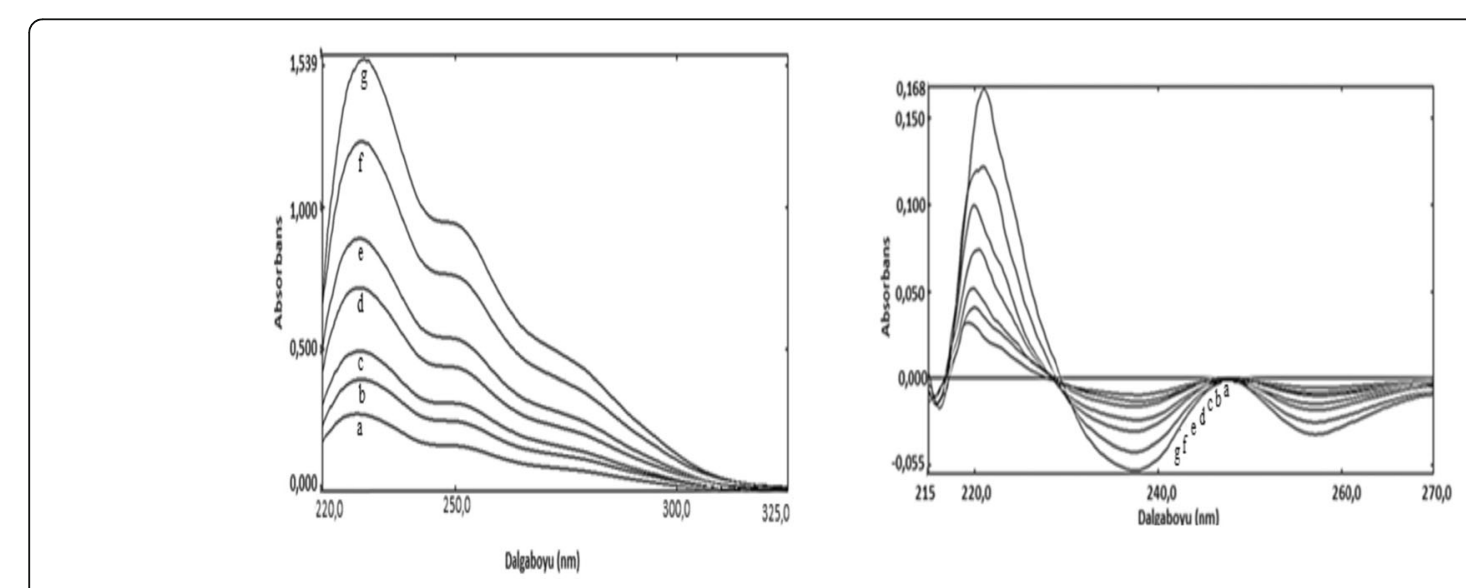

Fig. 4 Direct UV and first derivative UV spectrum of (a) $6.0 \mu \mathrm{g} \mathrm{mL}^{-1}$, (b) $8.0 \mu \mathrm{g} \mathrm{mL} L^{-1}$, and (c) $10.0 \mu \mathrm{g} \mathrm{mL} L^{-1}$, (d) $14.0 \mu \mathrm{g} \mathrm{mL} L^{-1}$, (e) $18.0 \mu \mathrm{g} \mathrm{mL}$, (f) $24.0 \mu \mathrm{g} \mathrm{mL}{ }^{-1}$, and $(\mathbf{g}) 30.0 \mu \mathrm{g} \mathrm{mL}{ }^{-1}$ VRT in $0.02 \mathrm{M}$ acetate buffer 
Table 3 Linearity and regression values for proposed methods

\begin{tabular}{llll}
\hline Method & RP-HPLC & \multicolumn{2}{l}{ Derivative spectrophotometry } \\
\hline Wavelength, $\mathrm{nm}$ & 225.0 & 237.7 & 257.2 \\
Working range $\left(\mu \mathrm{g} \mathrm{mL}^{-1}\right)$ & $10.0-70.0$ & $6.0-30.0$ & $6.0-30.0$ \\
Slope $\left(\mu \mathrm{g} \mathrm{mL}^{-1}\right)$ & 0.1116 & 0.0018 & 0.0011 \\
Intercept & 0.0770 & 0.0015 & 0.0005 \\
Correlation coefficient, $R^{2}$ & 0.9998 & 0.9999 & 0.9997 \\
LOD $\left(\mu \mathrm{g} \mathrm{mL}^{-1}\right)$ & 0.243 & 0.9623 & 0.5746 \\
LOQ $\left(\mu \mathrm{gL}^{-1}\right)$ & 0.811 & 3.2075 & 1.5486 \\
\hline
\end{tabular}

column was chosen, which gave the best results as shown in Table 1.

Forced degradation experiments were conducted to analyze stability-indicating properties and specificity of the suggested method. The degradation of sample solutions under stress conditions was determined. VRT and CAF were exposed to thermal, acid, base, oxidative, and photolytic degraded solutions passes the purity test (Table 2). The respective distinct chromatograms were given in Fig. 3. During the degradation study, VRT was been degraded higher in oxidation condition and was found to be stable in thermal, acid, base, and photolytic conditions.

In order to prove the validity of the developed methods, the parameters reported in the sources were selected for the method validity tests, and the relevant validity criteria were accepted [22]. For this purpose, validation studies, linearity, range, sensitivity, precision, recovery, repeatability, etc. parameters were investigated and statistical evaluations were made. Although the study with UPLC-MS/MS method is more sensitive in the literature, it is an expensive method. Our RP-HPLC and spectrophotometric studies are simple to be used in routine laboratories [6, 7]. MS/MS method was used for the degradation products in the reported study. However, in our study, degradation products were determined by the DAD detector. Chromatographic

Table 4 Inter-day and Intra-day variability of RP-HPLC for determining VRT concentrations

\begin{tabular}{llllll}
\hline & \multicolumn{2}{l}{ Intra-day variability } & & \multicolumn{2}{l}{ Inter-day variability } \\
Added $(\boldsymbol{\mu g} / \mathbf{m L})$ & Recovery (\%) & RSD $\%$ & & Recovery (\%) & RSD \% \\
\cline { 1 - 1 } RP-HPLC & 100.51 & 0.19 & 98.96 & 0.39 \\
30.0 & 99.97 & 0.53 & 99.49 & 0.57 \\
40.0 & 101.5 & 0.18 & 100.69 & 0.34 \\
50.0 & 98.21 & 1.04 & 98.96 & 1.43 \\
Derivative spectrophotometry & & & 1.17 \\
30.0 & 97.95 & 1.15 & 98.23 & 1.64 \\
40.0 & 100.5 & 0.87 & 97.25 & \\
50.0 & & & &
\end{tabular}

Table 5 Results of the application of proposed methods for Brintellix ${ }^{\circledR}$ tablets

\begin{tabular}{llll}
\hline Sample no. & \multicolumn{3}{l}{ Amount found, $\mathbf{m g}$} \\
\cline { 2 - 4 } & RP-HPLC & \multicolumn{2}{l}{ Derivative spectrophotometry } \\
\cline { 3 - 4 } & & $\mathbf{2 3 7 . 7} \mathbf{~ n m}$ & $\mathbf{2 5 7 . 2} \mathbf{~ n m}$ \\
\hline 1 & 10.07 & 9.51 & 10.26 \\
2 & 10.00 & 9.51 & 10.26 \\
3 & 10.23 & 9.51 & 9.91 \\
4 & 9.87 & 9.73 & 10.26 \\
5 & 10.11 & 9.51 & 10.62 \\
Mean value*, mg & 10.06 & 9.55 & 10.26 \\
Labeled amount, mg & 10.00 & 10.00 & 10.00 \\
p: 0,05 C.L, & $10.06 \pm 0.16$ & $9.55 \pm 0.18$ & $10.26 \pm 0.32$ \\
RSD & 1.33 & 1.52 & 2.45 \\
\hline
\end{tabular}

*Value $=$ average $\pm \mathrm{ts} / \sqrt{ } \mathrm{N}(\mathrm{N}=5$ and at $95 \%$ confidence level $)$

separation was finished within $2.0 \mathrm{~min}$ in our study. The system suitability parameters for VRT were found to be more sensitive compared to the studies in the literature. Additionally, it is an expensive method. Our study is simple to be used in routine laboratories and its analysis time is short and suitable for green chemistry compared to the studies in the reported literature. Our applied method is very sensitive and found LOQ value low [15].

The vortioxetine was analyzed as simple, fast, and suitable for green chemistry which has no required expensive equipments and software for the derivative method. LOD and LOQ values indicate that both methods are sensitive. Correlation coefficients of the methods are close to 1.0 which supports the sensitivity. Intra- and inter-day analyses were performed, and the results that are obtained showed that the purposed methods are precise.

\section{Conclusion}

The newly RP-HPLC and first derivative spectrophotometric methods have been proven to be sensitive, precise, accurate, and rapid. These described methods were also compared statistically via calculating $t$ and $f$ values and no difference was found between methods.

Table 6 Statistical analysis of results obtained by the proposed methods at $95 \%$ confidence limit

\begin{tabular}{llll}
\hline Method & Mean recovery, \% & RSD of recovery, \% & $\boldsymbol{N}$ \\
\hline RP-HPLC & $100.7 \pm 1.80$ & 1.41 & 5 \\
Der. spec. & $99.0 \pm 1.78$ & 0.48 & 5 \\
$F$ test significance & $1.30(F$ tabulated $=6.29)$ & & \\
$t$ test significance & $0.80(t$ tabulated $=2.78)$ & \\
\hline
\end{tabular}


Purposed methods were applied to the tablet formulation successfully. Since the proposed methods can be used in many control laboratories for the quantification of VRT in pharmaceutical formulations.

\section{Abbreviations}

RP-HPLC: Reverse phase-high performance liquid chromatography; VRT: Vortioxetine; CAF: Caffeine; UV: Ultraviolet; ICH: International Conference on Harmonization; LC-MS/MS: Liquid chromatography-mass spectrometry/ mass spectrometry; UPLC-MS/MS: Ultra performance liquid chromatographymass spectrometry/mass spectrometry; DAD: Diode array detector; 5-HT: 5Hydroxytryptamine; SD: Standard deviation; RSD: Relative standard deviation; LOD: Limit of detection; LOQ: Limit of quantification; IS: Internal standard

\section{Acknowledgements}

This work is produced from the master thesis of Cansu ALVER (Ankara University, Health Science Institute). This research has been supported by Ankara University Scientific Research Projects Coordination Unit (Project Numbers: 19 L0237001; 15 L0237007).

\section{Authors' contributions}

NE designed, developed, and supervised experiments, analyzed data, and wrote the paper. CA performed experiments. GT helped to draft the final manuscript. All authors read and approved the final manuscript.

\section{Funding}

No funding was received.

\section{Availability of data and materials}

All data and materials are available upon request.

\section{Ethics approval and consent to participate}

Not applicable

\section{Consent for publication}

Not applicable

\section{Competing interests}

The authors declare that they have no competing interests.

\section{Author details}

${ }^{1}$ Faculty of Pharmacy, Department of Analytical Chemistry, Ankara University, Tandoğan, Ankara, Turkey. ${ }^{2}$ Faculty of Pharmacy, Department of Analytical Chemistry, Bezmialem Vakif University, Fatih, Istanbul, Turkey.

Received: 27 August 2020 Accepted: 2 November 2020

Published online: 11 December 2020

References

1. D'Agostino A, English CD, JA R (2015) Vortioxetine (Brintellix): a new serotonergic antidepressant. Drug Forecast P\&T 40(1):36-40

2. Deerfield, Illinois: Takeda Pharmaceuticals (2013) America. Brintellix (vortioxetine) pack insert. https://www.lundbeck.com/upload/us/files/pdf/2 013 Releases/BrintellixApprovalRelease.pdf.

3. Wesolowska A, Tatarczynska E, Nikiforuk A, Chojnacka-Wojcik E (2007) Enhancement of the anti-immobility action of antidepressants by a selective 5-HT7 receptor antagonist in the forced swimming test in mice. Eur J Pharmacol 555(1):43-47

4. Brintellix. In: Drugdex (2016) Greenwood Village, Colorado: Thompson Micromedex; 1974-2008. www.micromedex.com. Accessed 2016.

5. Bang-Andersen $B$, Ruhland $T$, Jorgensen $M$, Smith $G$, Frederiksen $K$, Jensen KG, Zhong H, Nielsen SM, Hogg S, Mork A, Stensbol TB (2011) Discovery of 1-[2-(2,4-dimethylphenyl sulfanyl) phenyl]piperazine (Lu AA21004): a novel multimodal compound for the treatment of major depressive disorder. J Med Chem 54(9):3206-3221

6. Gu EM, Huang C, Liang B, Yuan L, Lan T, Hu G, Zhou H (2015) An UPLC-MS/ MS method for the quantitation of vortioxetine in rat plasma: application to a pharmacokinetic study. J Chromatogr B 997:70-74

7. Yi Y, Ren G, Zheng M, Zhao D, Li N, Chen X, Lu Y (2020) Simultaneous determination of deuterated vortioxetine and its major metabolite in human plasma by UPLC-MS/MS and application to a pharmacokinetic study in healthy volunteers. J Chromatogr B 1138:121955

8. Dong SB, Yan Z, Yang H (2016) A sensitive precolumn derivatization method for determination of piperazine in vortioxetine hydrobromide using a C8 column and high-performance liquid chromatography-mass spectrometry. Anal Sci 32(12):1333-1338.

9. Henriette KU, Martin J, Henrik P, Lars D (2011) Biosynthesis and identification of an $\mathrm{N}$-oxide/N-glucuronide metabolite and first synthesis of an N-O-glucuronide metabolite of Lu AA21004. Drug Metab.Dispos. 39(12): 2264-2274

10. Areberg J, Luntang-Jensen M, Søgaard B, Nilausen D $\varnothing$ (2012) Occupancy of the serotonin transporter after administration of Lu AA21004 and its relation to plasma concentration in healthy subjects. Basic Clin Pharmacol Toxicol 110:401-404

11. Wroblewski K, Petruczynik A, Buszewski B, Szultka-Mlynska M, KarakulaJuchnowicz H, Waksmundzka-Hajnos M (2017) Determination of vortioxetine in human serum and saliva samples by HPLC-DAD and HPLCMS. Acta Chromatographica 29(3):325-344

12. Lei L, Na C, Xingling M, Kaihe X, Lili S, Qiaogen Z, Lili Y (2016) Stabilityindicating reversed-phase HPLC method development and characterization of impurities in vortioxetine utilizing LC-MS, IR and NMR. J Pharm Biomed Anal 117:325-332

13. Kall MA, Rohde M, Jorgensen M (2015) Quantitative determination of the antidepressant vortioxetine and its major human metabolite in plasma. Bioanalysis 7(22):2881-2894

14. Kertys M, Krivosova M, Ondrejka I, Hrtanek I, Tonhajzerova I, Mokry J (2020) Simultaneous determination of fluoxetine, venlafaxine, vortioxetine and their active metabolites in human plasma by LC-MS/MS using one-step sample preparation procedure. J Pharm Biomed Anal 181:113098

15. De Diego M, Correa D, Mennickent S, Godoy R, Vergara C (2018) Determination of vortioxetine and its degradation product in bulk and tablets, by LC-DAD and MS/MS methods. Biomed Chromatogr 32(11):e4340

16. Oin M, Qiao H, Yuan Y, Shao O (2018) A quantitative LC-MS/MS method for simultaneous determination of deuvortioxetine, vortioxetine and their carboxylic acid metabolite in rat plasma, and its application to a toxicokinetic study. Anal Methods 10(9):1023-1031

17. Petruczynik A, Wroblewski K, Wojtanowski K, Mroczek T, Juchnowicz D, Karakula-Juchnowicz H, Tuzimki T (2020) Comparison of various chromatographic systems for identification of vortioxetine in bulk drug substance, human serum, saliva, and urine samples by HPLC-DAD and LC QTOF-MS. Molecules 25(11):2483

18. Wroblewski K, Petruczynik A, Tuzimki T, Prajsnar K, Przygodzk D, Buszewicz G, Karakula-Juchnowicz H, Rog J, Morylowska-Hajnos J, WaksmundzkaHajnos M (2019) Optimization of chromatographic systems for analysis of selected psychotropic drugs and their metabolites in serum and saliva by HPLC in order to monitor therapeutic drugs. Open Chem 17(1):1361-1373

19. Chen Y, Zhu YL, Qiu CZ, Pan QM, Liu WY, Qiu XJ (2019) A simple HPLC method for the determination of vortioxetine in rabbit plasma and its application to a pharmacokinetic study. Latin Am J Pharm 38(6):1111-1115

20. Dousa M, Klvana R, Doubsky J, Srbek J, Richter J, Exner M, Gibala P (2016) HILIC-MS determination of denotoxic impurity of 2-chloro-N-(2-chloroethyl) ethanamine in the vortioxetine manufacturing process. J Chromatogr Sci 54(2):119-124

21. Meloun M, Pilarova L, Capova A, Pekarek T (2018) The overlapping thermodynamic dissociation constants of the antidepressant vortioxetine using UV-VIS multiwavelength pH-titration data. J Solution Chem 47(5):806-826

22. The International Conference on Harmonisation ICH Technical Requirements for Registration of Pharmaceuticals for Human Use on Validation of Analytical Procedures (2005)

\section{Publisher's Note}

Springer Nature remains neutral with regard to jurisdictional claims in published maps and institutional affiliations. 